\title{
Is Single-Drug Prophylaxis in Migraine Prevention a Better Option than Combination Therapy? An Observational Study in a Rural Tertiary Care Center in North West India
}

\author{
Monika Angra ${ }^{1}$ Amit Bhardwaj ${ }^{1} \quad$ Ashish Sharma $^{1}$ \\ Piyush Sharma ${ }^{2}$
${ }^{1}$ Department of Neurology, Dr. Rajendra Prasad Government Medical College, Kangra, Himachal Pradesh, India
2Department of Community Medicine, Dr. Rajendra Prasad \\ Government Medical College, Kangra, Himachal Pradesh, India
}

\section{Girish Kumar ${ }^{1}$ Mandeep Singh ${ }^{1}$ Gurleen Kaur ${ }^{1}$}

\begin{abstract}
Address for correspondence Girish Kumar, MD, Department of Neurology, Dr. RPGMC Tanda, Kangra, Himachal Pradesh, India (e-mail: drgirishsharma70@gmail.com).
\end{abstract}

\begin{abstract}
Keywords

- migraine

- monotherapy in migraine

- preventive therapy

- single-drug therapy combination therapy in migraine

Background Migraine is a primary headache disorder that has a great impact on quality of life of patients. Pharmacologic therapy may be given in acute or abortive form and in the form of preventive therapy. In what form is preventive therapy to be given? Whether monotherapy is to be used or combination therapy? In what cases does combination therapy fare better than monotherapy? These queries are still unanswered.

Materials and Methods All patients with headache reporting to the outpatient department were screened, and those fulfilling inclusion criteria were included in the study. Those patients who had chronic daily headache (headache for 15 or more days in a month) or who had other comorbidities and those who were taking any other drugs and were pregnant were excluded from the study. Baseline parameters, duration of headache, frequency of attacks, severity, and location of headache, triggers, and aggravating factors were recorded. Then, patients were started on abortive and preventive therapy. The follow-up was done at 3 and 6 months and if required earlier. At each follow-up, data regarding frequency, severity, and adverse effects were recorded and analyzed.

Results We studied 105 patients of migraine, out of which 15 (14.3\%) were males and $90(85.7 \%)$ were females. Moreover, most (72\%) of the patients were of the age group of 30 to 49 years. Only 11 (10.5\%) patients required three or more preventive medicines for the control of headache and rest 94 (89.5\%) patients were controlled on single (49 patients, i.e., $46.7 \%$ ) or two 45 , that is, $42.9 \%$ preventive medicines 49 . Conclusion For the newly diagnosed migraine cases, the single-drug preventive therapy is more useful than the combination of drugs.
\end{abstract}

\section{Introduction}

Migraine is a primary headache disorder that has a great impact on quality of life of the patients. ${ }^{1}$ There is evidence in literature that patients with migraine have a worse quality of life than patients with other chronic diseases such as diabetes and hypertension. ${ }^{2}$ It is easy to diagnose and treat the disease, but many aspects of treatment are still in the gray area. Pharmacologic therapy may be given in acute or abortive form and in the form of preventive therapy. Preventive 
therapy is the backbone of migraine treatment. It is used to reduce the frequency, duration, or severity of attacks. ${ }^{3}$ Additional benefits may include enhanced response of acute treatment, improved patient ability to function, and reduction of disability. ${ }^{4}$ However, clinicians have many unanswered queries regarding preventive therapy like the following: In what form is preventive therapy to be given? ${ }^{5}$ Whether monotherapy is to be used or combination therapy? In what cases does combination therapy fare better than monotherapy?

\section{Materials and Methods}

The study was conducted at tertiary care center in rural Northwest India. In addition to new patients, we mostly see patients referred from other departments of our institute and patients from other hospitals of the state. All patients with headache reporting to the outpatient department were screened and those fulfilling IHS 3 (International Headache Society) criteria $^{6}$ for migraine and those who were in the age group of 18 to 50 years, with a stable headache pattern for at least 6 months, with two or more attacks per month were included in the study. Those patients who had chronic daily headache (headache for 15 or more days in a month) as the patients with chronic daily headache are least likely to respond to single preventive drug therapy or who had other comorbidities, those who were taking any other drugs (antiepileptic drugs, neuroleptics, $\beta$-blockers for any other ailments than migraine), and those who were pregnant were excluded from the study. Informed consent was taken before inclusion in the study.

Baseline parameters for each patient were recorded in the prescribed pro forma. The duration of headache, frequency of attacks, severity, and location of headache, triggers, and aggravating factors were recorded. The systemic examination was done to rule out any focal neurologic deficit. Fundoscopic examination was done for each patient to rule out papilledema. Blood parameters hemogram, erythrocyte sedimentation rate, and renal and liver function tests were done at baseline. Urine pregnancy test was done in female patients to rule out pregnancy. Imaging computed tomography/magnetic resonance imaging of brain was done in cases where there was worsening of symptoms, and if neuroimaging suggests any other diagnosis, those patients were excluded from the study.

Then patients were started on abortive and preventive therapy. Patients were advised to maintain headache diary to record the frequency and severity of headache. The follow-up was done at 3 and 6 months and if required earlier. At each follow-up, data regarding frequency, severity, and adverse effects were recorded. Data were collected and analyzed.

\section{Statistics}

Data were entered in Microsoft excel (Microsoft Corporation One Microsoft Way Redmond, WA 98052-6399, United States) and analysis was done with EPI Info 7 (Centers for Disease Control and Prevention, Atlanta, Georgia, United States) and frequency and percentage were calculated for each parameter. The chi-square test was applied for the effect of number of medication on the frequency of headache at 3 and 6 months of migraine treatment.

\section{Results}

We studied 105 patients of migraine, out of which 15 (14.3\%) were male and 90 (85.7\%) were female. Moreover, most (72\%) of the patients were of the age group of 30 to 49 years. The duration of migraine was $<6$ months in $4(3.8 \%)$ patients, between 7 and 12 months in 6 (5.7\%) patients, 13 to 60 months in $34(32.4 \%)$ patients, $>60$ months in 61 patients, that is, $58.1 \%$ (-Table 1). At the start of the study, 54 (51\%) patients had frequency of 5 to 9 episodes per month and $20(19 \%)$ had $<4$ episodes per months and 31 (29.5\%) had a frequency of 10 or more episodes per month. At 3 months of treatment, 79 (75.2\%) patients had frequency of $<4$ episodes per month and $24(22.9 \%)$ patients had frequency of 5 to 9 episodes per month, and only $2(1.9 \%)$ patients had the frequency of 10 or more episodes per month. At 6 months of treatments, 96 (91\%) patients had frequency of headache $<4$ episodes per month and 8 (7.6\%) patients had 5 to 9 episodes per month and only 1 patient had 10 or more headache episodes per month (-Table 2). Only 11 (10.5\%) patients

Table 1 Basic parameters

\begin{tabular}{|c|c|}
\hline & Total number of patients ( $n=105), n(\%)$ \\
\hline Male & $15(14.3)$ \\
\hline Female & $90(85.7)$ \\
\hline \multicolumn{2}{|c|}{ Age, years } \\
\hline 10-19 & $3(2.9)$ \\
\hline $20-29$ & $26(24.8)$ \\
\hline $30-39$ & $38(36.2)$ \\
\hline $40-49$ & $29(36.2)$ \\
\hline $50-59$ & $4(3.8)$ \\
\hline $60-69$ & $5(4.8)$ \\
\hline \multicolumn{2}{|c|}{ Duration, months } \\
\hline$<6$ & $4(3.8)$ \\
\hline $7-12$ & $6(5.7)$ \\
\hline $13-60$ & $34(32.4)$ \\
\hline$>60$ & $61(58.1)$ \\
\hline
\end{tabular}

Table 2 Effects of preventive medications on frequency of headache episodes

\begin{tabular}{|l|l|l|l|}
\hline Number of episodes & Frequency at onset (\%) & Frequency at 3 mo (\%) & Frequency at 6 mo (\%) \\
\hline$<4$ episodes/month & $20(19)$ & $79(75.2)$ & $96(91.4)$ \\
\hline $5-9$ episodes/month & $54(51.4)$ & $24(22.9)$ & $8(7.6)$ \\
\hline 10 and more episodes/month & $31(29.5)$ & $2(1.9)$ & $1(1)$ \\
\hline
\end{tabular}


required three or more preventive medicines for the control of headache and rest $94(89.5 \%)$ patients were controlled on single ( 49 patients, i.e., $46.7 \%$ ) or two 45 , that is, $42.9 \%$ preventive medicines 49 ( - Table 3 ). Severity of migraine was $<3$ in 1 patient (1\%), between 4 and 7 in 33 (31.4\%) patients, and $>8$ in $71(67.6 \%)$ patients (-Table 4).

Of 49 (46.7\%) patients who were started on single preventive medicine, 24 (48.97\%) were having $<4$ episodes of headache per month and 22 (44.89\%) had 5 to 9 episodes per month, and $3(6.10 \%)$ were having 10 and more episodes per month. At the end of 3 months of treatment, 41 (83.63\%) had $<4$ episodes of headache per month and 8 (16.32\%) were having 5 to 9 episodes of headache per month, and none had $>10$ episodes per month. Moreover, at the end of 6 months, 47 (95.91\%) were having $<4$ episodes per month and $2(4.08 \%)$ had 5 to 9 episodes per month and none of them had 10 or more episodes.

Forty-five (42.9\%) patients were started on two preventive drugs and out of those, 16 (35.5\%) patients had $<4$ episodes of headache per month and 22 (48.88\%) were having 5 to 9 episodes per month and $7(15.55 \%)$ had 10 and more episodes per months at the start of treatment. In addition, at the 3 months of treatment, $32(71.11 \%)$ had $<4$ episodes of headache per month and 12 (26.66\%) were having 5 to 9 episodes of headache per month and 1 (2.22\%) had $>10$ episodes per month. Moreover, at the end of 6 months, 42 (93.33\%) were having

Table 3 Number and type of preventive medications used in migraine patients

\begin{tabular}{|l|l|}
\hline $\begin{array}{l}\text { Total number of preventive } \\
\text { medicines used }\end{array}$ & Number of patients (\%) \\
\hline 1 & $49(46.7)$ \\
\hline 2 & $45(42.9)$ \\
\hline 3 & $11(10.5)$ \\
\hline Type of preventive medicines & $47(44.8)$ \\
\hline Flunarizine & $7(6.7)$ \\
\hline Propranolol & $20(19)$ \\
\hline Flunarizine and propranolol & $16(15.2)$ \\
\hline Flunarizine and amitriptyline & $11(10.5)$ \\
\hline $\begin{array}{l}\text { Flunarizine and amitriptyline } \\
\text { and propranolol }\end{array}$ & $1(1)$ \\
\hline Amitriptyline and propranolol & $1(1)$ \\
\hline Propranolol and topiramate & $2(1.9)$ \\
\hline Others &
\end{tabular}

$<4$ episodes per month and $2(4.44 \%)$ had 5 to 9 episodes per month and $1(2.22 \%)$ was having 10 or more episodes.

Of $11(10.5 \%)$ patients who were started on three or more preventive medicine, 2 (18.18\%) patients were having $<4$ episodes of headache per month and $6(54.54 \%)$ were having 5 to 9 episodes per month and 3 (27.27\%) had 10 and more episodes per month at the start of treatment. At the 3 months of treatment, 6 (54.54\%) were having < 4 episodes of headache per month and $4(36.36 \%)$ had 5 to 9 episodes of headache per months and 1 (9.09\%) had $>10$ episodes per month. And, at the end of 6 months, 7 (63.63\%) were having $<4$ episodes per month and $4(36.36 \%)$ had 5 to 9 episodes per month and none had 10 or more episodes (-Table 5 ).

\section{Discussion}

Of 105 patients, 90 were females. The majority (63\%) belong to 30 to 50 years of age. The duration of illness was $>5$ years in $59 \%$ of patients. The cause of the late presentation of patients to the hospital may be when the headache attacks become too frequent or when over-the-counter drugs become ineffective in controlling their symptoms. Most patients ignore the early attacks and visit the neurologist only when the headache becomes chronic or the abortive therapy does not give much relief. Most of the patients do not get preventive therapy at the right time in the course of the disease. ${ }^{3}$ The role of preventive therapy in the management of migraine needs to be emphasized to the health care providers. Preventive medicines reduce attack frequency and improve the response to the acute treatment and quality of life of the patient. ${ }^{3}$ Monotherapy should be the rule in migraine prevention. ${ }^{7}$ Drug combinations have been used for the resistant migraine prevention. ${ }^{8}$ There are studies that have suggested that combination therapy should be used more frequently and as a first step in the therapeutic plan for more complete and fast response. ${ }^{9}$ However, few of the studies have shown that using two or more drugs are associated with an increase in adverse effects. ${ }^{10}$ In our study, we have found that using the single drug for the preventive therapy in migraine has shown a better response in decreasing the frequency of headache at 6 months of treatment as compared with the combination of two or more drugs. The difference was statistically significant with $p=0.003$. Our study confirms the fact that combination therapy in prophylactic treatment may be useful in the resistant and difficult-to-control cases but for the newly diagnosed cases the single-drug therapy is more useful as the combination of drugs will not only increase the adverse effects and decrease the patient compliance but also increase the cost of the treatment as well.

Table 4 Severity of headache in migraine patients on preventive therapy

\begin{tabular}{|l|l|l|l|}
\hline & Severity at onset (\%) & Severity at 3 mo (\%) & Severity at 6 mo (\%) \\
\hline $0-3$ & $1(1)$ & $10(8)$ & $69(61)$ \\
\hline $4-7$ & $33(31.4)$ & $89(85)$ & $31(30)$ \\
\hline Above 8 & $71(67.6)$ & $68(6)$ & $5(4)$ \\
\hline
\end{tabular}


Table 5 Effect of number of preventive medications on the frequency of headache episodes at 3 and 6 months of treatment

\begin{tabular}{|c|c|c|c|c|c|}
\hline \multirow[t]{2}{*}{ Frequency of headache } & \multicolumn{3}{|c|}{ Number of preventive medicines } & \multirow[t]{2}{*}{ Total number } & \multirow[t]{2}{*}{$p$-Value } \\
\hline & 1 & 2 & 3 & & \\
\hline \multicolumn{6}{|l|}{ At 0 month (\%) } \\
\hline$<4$ episodes/month & $24(48.97)$ & $16(35.55)$ & $2(18.18)$ & 42 & \multirow[t]{4}{*}{0.158} \\
\hline 5-9 episodes/month & $22(44.89)$ & $22(48.88)$ & $6(54.54)$ & 50 & \\
\hline 10 and more episodes/month & $3(6.10)$ & $7(15.55)$ & $3(27.27)$ & 13 & \\
\hline Total & $49(100)$ & $45(100)$ & $11(100)$ & 105 & \\
\hline \multicolumn{6}{|l|}{ At 3 months (\%) } \\
\hline 1-4 episodes/month & $41(83.67)$ & $32(71.11)$ & $6(54.54)$ & 79 & \multirow[t]{4}{*}{0.125} \\
\hline 5-9 episodes/month & $8(16.32)$ & $12(26.66)$ & $4(36.36)$ & 24 & \\
\hline 10 and more episodes/month & 0 & $1(2.22)$ & $1(9.09)$ & 2 & \\
\hline Total & $49(100)$ & $45(100)$ & $11(100)$ & 105 & \\
\hline \multicolumn{6}{|l|}{ At 6 months (\%) } \\
\hline 1-4 episodes/month & $47(95.91)$ & $42(93.33)$ & $7(63.635)$ & 96 & \multirow[t]{4}{*}{0.003} \\
\hline 5-9 episodes/month & $2(4.08)$ & $2(4.44)$ & $4(36.36)$ & 8 & \\
\hline 10 and more episodes/month & 0 & $1(2.22)$ & 0 & 1 & \\
\hline Total & $49(100)$ & $45(100)$ & $11(100)$ & 105 & \\
\hline
\end{tabular}

\section{Conclusion}

For the newly diagnosed migraine cases, the single-drug preventive therapy is much useful as it not only has better patient compliance and tolerability but also has better response in decreasing the headache frequency than the combination of drugs.

\section{Funding}

None.

\section{Conflict of Interest}

None declared.

\section{References}

1 Lipton RB, Hamelsky SW, Stewart WF, Epidemiology and Impact of Headache. New York: Oxford University Press; 2001 85-107

2 Osterhaus JT, Townsend RJ, Gandek B. Ware JE Jr. Measuring the functional status and well-being of patients with migraine headache. Headache 1994;34(6):337-343

3 Silberstein SD. Preventive migraine treatment. Continuum (Minneap Minn) 2015;21(4, Headache):973-989
4 Lipton RB, Silberstein SD. Why study the comorbidity of migraine? Neurology 1994;4410) (suppl 7):S4-S5

5 Adelman JU, Brod A, Von Seggern RL, Mannix LK, Rapoport AM. Migraine preventive medications: a reappraisal. Cephalalgia 1998;18(9):605-611

6 Olesen J Bendtsen L Goadsby PDucros A, Dodick DW, Russell $\mathrm{MB}$, et al. The International Classification of Headache Disorders; -; 2018 38:1-211

7 Tfelt-Hansen P, Welch KM, General principles of pharmacological treatment of migraine. In: Olesen J, Tfelt-Hansen P, Welch KM, eds. The Headaches. 2nd edition. Philadelphia, PA: Lippincott, William \& Wilkins; 2000 385-390

8 Silberstein SD, Saper JR, Freitag FG, Migraine: Diagnosis and treatment. In: Silberstein SD, Lipton RB, Dalessio DJ, eds. Wolff's Headache and Other Head Pain. Oxford: Oxford University Press; 2001 121-237

9 Bordini CA, Mariano da Silva H, Garbelini RP, Teixeira SO, Speciali JG. Effect of preventive treatment on health-related quality of life in episodic migraine. J Headache Pain 2005;6(5):387-391

10 Pascual J, Leira R, Láinez JM. Combined therapy for migraine prevention? Clinical experience with a beta-blocker plus sodium valproate in 52 resistant migraine patients. Cephalalgia 2003;23(10):961-962 